\title{
Chemical, Physical, Textural and Sensory Evaluation on Italian Rice Varieties
}

\author{
C. Simonelli ${ }^{1, *}$, L. Galassi ${ }^{2}$, M. Cormegna ${ }^{1}$, P. Bianchi ${ }^{2}$ \\ ${ }^{1}$ Ente Nazionale Risi (ENR) -Chemical Laboratory (LCM), Strada per Ceretto 11, Castello d'Agogna (PV), Italy \\ ${ }^{2}$ Regional Agency for Agriculture and Forestry (ERSAF) - Laboratory of Sensory Analysis, via Carpaneta 7, Bigarello (MN), Italy
}

Copyright $\bigcirc 2017$ by authors, all rights reserved. Authors agree that this article remains permanently open access under the terms of the Creative Commons Attribution License 4.0 International License

\begin{abstract}
The characterization of ten Italian rice varieties has been carried out by chemical analysis which requires the use of more or less sophisticated equipment and of technicians trained to the application of analytical methods. Beside this type of analysis, defined as "traditional", it is carried out a descriptive evaluation of the samples from a sensory point of view. Descriptive analysis is a new experience in the evaluation of Italian rice that allows describing and quantifying the sensory properties of the different varieties. As with traditional analysis the calibration of instruments is fundamental and the choice of the adequate analytical method, so the equipment for sensory analysis is the basic choice of assessors who will be part of the panel and their training. Ten heterogeneous varieties of Italian rice have been characterized both from a traditional point of view, namely, chemical, physical and textural (length and width, gel-time, resistance to extrusion, stickiness, amylose content), and sensory, involving a panel of selected, chosen and trained tasters. The analytical data will then be compared in order to bring out similarities and differences. It appears that there is agreement between the sensory analysis and the chemical physical and textural characterization of milled rice. The sensory characterization undoubtedly provides a more complete and accurate information than the instrumental one.
\end{abstract}

Keywords Amylose, Gelatinization Time, Panel Test, Resistance to Extrusion, Rice, Sensory Evaluation, Stickiness

\section{Introduction}

Rice (Oryza sativa) is a member of the Poaceae or Graminaceae family. It is a plant with ancient cultivation, native to South-east Asia. Along with wheat and corn, it is an important source of energy for sustaining the world's population; rice is the staple food for more than half the world's population providing more than one fifth $(20 \%)$ of the total calories consumed worldwide by humans [1]. FAO estimates that nearly 3 billion people share the culture, traditions and potential of rice, in the different parts of the world. To date, Italy is one of the most important producer of rice in Europe (about 227000 hectares in 2015 [2]) and Italian rice is considered a high-quality product (1/3 consumed and $2 / 3$ exported).

In Italy there are more than 180 different rice varieties which are submitted to a special legislation (Italian National Register of Varieties). All of them should be peculiar in agronomical and/or physicochemical and structural features to be registered as new rice variety.

In rice, quality traits encompass physical appearance, cooking and sensory properties, and nutritional value. The value of each trait, like length of the grain, varies according to local cuisine and culture. Predictable expression of these traits across seasons and years gives a cultivar its reputation [3].

Rice is commonly consumed as milled or white rice, which is produced by removing the hull and bran layers of the rough rice kernel in dehulling and milling processes, respectively. The rice milling operation involves dehulling (removal of hulls from rough rice kernels) to give brown rice, and milling (removal of bran from brown rice).

There are a few properties that characterize rice kernels: amylose content, biometrics value (length and width of kernel), texture properties (hardness and stickiness) and gelatinization time.

In Italy there is a specific organization for the protection of rice cultivation: Ente Nazionale Risi (ENR). ENR has several Departments and structures for many scientific competences (chemical, agronomical, biotechnological, and economical); in particular in the Rice Research Centre there is the Chemical Merceological Laboratory (LCM), called "laboratory" or "LCM". The LCM was made in 1980's and has been accredited since 2007 by Accredia (the Italian Accreditation Body) for specific analysis on rice.

ERSAF is the agricultural body of Lombardy.

Technical public services cover all fields of regional agriculture and forestry. Among them, the valorization and sensory characterization of agricultural food products like rice can be found. 
Sensory profiles have been carried out by the sensory analysis laboratory, made in 1999 and accredited UNI EN ISO 17025 since 2005.

Sensory profiling of rice has been made for some years, covering different varieties of rice and different soils.

\subsection{Physical Characteristics}

\section{Aromaticity}

An interesting aspect from the point of view of the inclusion in the National (Italian) Register of Varieties is the presence / absence of aromaticity. Aromatic rice emits in cooking a characteristic scent similar to popcorn related to a pool of chemical compounds including, in particular, the 2-acetyl-pyrroline that some varieties of rice (called "aromatic rice") are able to synthesize.

\section{Dimensional characterization}

Rice grain has been classified as medium, long A, long B and round by the application of the EC Regulation 1308/2013 [4] (Annex III, Part 1), as reported below:

Table 1. Classification of rice by dimension of kernel

\begin{tabular}{ccc}
\hline Classification & Length $(\mathrm{L})$ & $\begin{array}{c}\text { Length } / \text { Width } \\
(\mathrm{L} / \mathrm{l}) \text { ratio }\end{array}$ \\
\hline Round & $\mathrm{L} \leqslant 5.2 \mathrm{~mm}$ & $\mathrm{~L} / 1<2$ \\
Medium & $5.2 \mathrm{~mm}<\mathrm{L} \leqslant 6.0 \mathrm{~mm}$ & $\mathrm{~L} / 1<3$ \\
Long A & $\mathrm{L}>6.0 \mathrm{~mm}$ & $2<\mathrm{L} / 1<3$ \\
Long B & $\mathrm{L}>6.0 \mathrm{~mm}$ & $\mathrm{~L} / 1 \geqslant 3$ \\
\hline
\end{tabular}

\subsection{Cooking and Eating Characteristics}

\section{Gelatinization time}

Starch gelatinization phenomena in a hot aqueous medium is influenced by various factors, such as time, temperature and components (moisture, salts, sugar, lipids, ...). Starch gelatinization phenomenon is described as a kind of chemical reaction process in which the ungelatinized part of the starch is changed into a gelatinized one [5]. Physically, starch consists of amorphous and crystallite regions and the gelatinization initially occur in the former.

Gelatinization time (or gel-time) is defined as the time necessary for $90 \%$ of the kernels to pass from their natural state to the gel state (ISO 14864) [6]. Gelatinization is the hydration process which confer the jelly-like state typical of the coagulated colloids, which are named "gels", on kernels (ISO 14864) [6]. The gel state is the condition reached as a consequence of gelatinization, when the kernel is fully transparent and absolutely free from whitish and opaque granules after being squashed between two glass plates (ISO 14864) [6].

Gel-time is correlated with the hydration process of starch when rice is cooked in water at high temperature. This process, first slow and then quick, induce an irreversible change in the physical structure of the starch. Its crystalline granules became colloidal, losing the characteristic of crystallinity [7].

The method of determination of gel-time is the "Ranghino test" described at first in 1966 [8]. This Italian analysis technique is adopted in most of the world laboratories and the importance of this determination is very well highlighted by its longevity: it was reviewed in 2007 in an important article [9].

Any Italian variety has a particular gel-time determined by the manual Ranghino method which is correlated to the cooking time of each variety [10]. Usually for Italian varieties of rice a gel time in a range of $14-24$ minutes is observed [1].

\section{Rice texture}

Cooked rice texture has been shown to govern the acceptance of rice by consumers when consumed as the whole grain. Texture has been defined as a multidimensional characteristic that only humans can perceive, define, and measure.

Thus, sensory evaluation is critical although instrumental measurement of textural properties is also common practice [11].

Although texture is multidimensional, resistance to extrusion (hardness) and stickiness are critical and these textural characteristics govern the palatability of cooked rice in Italian markets, with hardness being the most important and most commonly measured parameter. Rice texture is affected by factors such as variety, amylose content, and gelatinization temperature processing factors and cooking method. For instance, cooked rice with low amylose content is soft and sticky, while rice with high amylose is firm and fluffy [11].

\subsection{Chemical Characteristics}

\section{Proteins and lipids}

Proteins are most concentrated in the outer layers of the rice kernel, but significant amounts are also present in the endosperm [12].

Lipids can contribute to the quality of rice, influencing the nutritional and sensory, although not abundant components such as carbohydrates and proteins. The total concentration of fat in the caryopsis of brown rice is between 2 and $4 \%$, while concentration in the grain milled rice amounts to 0.3 to $0.6 \%$ (according to degree of milling) [12].

\section{Moisture}

Moisture content is the amount of water in the rice grain. In post-harvest handling, grain moisture content is generally expressed as the percentage of the water contained in the wet grain. Moisture of $14 \%$ or less is considered safe for storing grains; paddy should be dried to safe moisture content within 24 hours after harvesting to avoid damage and deterioration. Improper drying and storage practices lead to low grain or seed quality. 


\section{Amylose content}

The eating quality of rice is strongly influenced by amylose content [13].

Amylose content is considered the single most important characteristic for predicting rice cooking and processing behavior. Amylose content is directly related to water absorption, volume expansion, fluffiness, and separability of cooked rice. It is inversely related to cohesiveness, tenderness, and glossiness [11].

Amylose content is positively correlated with hardness and negatively correlated with stickiness [13].

\subsection{Aim of this Research}

The quality characterization of newly developed rice cultivars (from cereal chemistry approach and to find correlation between important properties) is mandatory to study their quality attributes and to compare their different properties with already studied cultivars for further improvement in the quality characteristics of under developped varieties of rice. The goal of this paper is to study chemical, textural, nutritional and sensorial characteristics of the different new rice cultivars grown in Italy.

\subsection{Sensory Analysis (ISO 6658:2005 [14])}

Sensory analysis is the science involved with the examination of the perceptible characteristics of foods.

The objectives of sensory analysis are of three types:

- to categorize, rank or describe the products;

- to distinguish between two or more products;

- to reassure that products do not differ.

A sensory analysis panel is made of people who have been selected and trained to perform sensory tasks.

Sensory analysis should be conducted in a dedicated test room where temperature, odours, sound, lighting are under control. Individual booths are usually used.

The preparation of samples is a key process of sensory analysis: it regards the presentation order, the number and expectoration of samples, the behaviour of assessors before the test and so on.

Descriptive tests are used to identify the specific sensory attributes present in the samples. The attributes are rating on an intensity scale and the results are used to determine a sensory profile for the product.

In consensus forecast profile methods, the panel arrives at a shared decision on the profile in the light of the discussion.

The average results can be compared statistically by using analysis of variance. There are also techniques of multivariate analysis.

\section{Materials and Methods}

The ten Italian rice varieties selected for the purpose are:
Aiace, Arborio, Baldo, Carnaroli, Loto (long A); Gange, S. Andrea, Thaibonnet (long B); Selenio (round); Vialone Nano (medium). The classification in: long $\mathrm{A}$ and $\mathrm{B}$, round and medium are done according to the European legislation, Reg. CE 1308/2013 [4].

\subsection{Choice of Varieties}

It was essential that the range of choices would allow each variety to bring out all the characteristics identified in the food rice [15]. It was therefore important that the varieties were very different. To identify the varieties to be submitted to the study, the LCM had considered the DM 13/05/10 [16] with the division of rice varieties in different groups (Comune o Originario, Semifino, Fino) and its data store showing the characterization of different variety of rice from 1984 to present [15].

Table 2. Selected rice Italian varieties

\begin{tabular}{|c|c|c|c|c|}
\hline $\mathrm{n}^{\circ}$ & Rice variety & $\begin{array}{c}\text { Group } \\
\text { (DM } \\
13 / 05 / 10)\end{array}$ & $\begin{array}{l}\text { Classification } \\
\text { (Reg. CE } \\
\text { 1308/2013) }\end{array}$ & Aromaticity \\
\hline 1 & Aiace & Fino & Long A & No \\
\hline 2 & Arborio & Superfino & Long A & No \\
\hline 3 & Baldo & Superfino & Long A & No \\
\hline 4 & Carnaroli & Superfino & Long A & No \\
\hline 5 & Gange & Superfino & Long B & Sì \\
\hline 6 & Loto & Fino & Long A & No \\
\hline 7 & Sant'Andrea & Fino & Long B & No \\
\hline 8 & Selenio & $\begin{array}{l}\text { Comune o } \\
\text { Originario }\end{array}$ & Round & No \\
\hline 9 & Thaibonnet & Superfino & Long B & No \\
\hline 10 & $\begin{array}{c}\text { Vialone } \\
\text { Nano }\end{array}$ & Semifino & Medium & No \\
\hline
\end{tabular}

\subsection{Chemical, Physical and Textural Properties}

In the LCM the following analytical determinations were carried out: length and width (UNI EN ISO 11746:2012 [17]) counting 100 kernels with an automatic counter machine (Contador) and coming to obtaining the analytical determination with an image analyzer WinSEEDLE (WinSEEDLE Pro, WSP STD4800, Regent Instrument).

For the determination of texture, rice samples were cooked with a rice steam cooker (SPL, F.lli Galli). Cooked rice texture was measured with a Texture Analyzer model TA.XT plus (Stable Micro Systems) using the compression test according to the ISO 11747:2012 [18] method (resistance to extrusion: hardness) and to an internal method [19], [20] for stickiness. $\mathrm{X} \mathrm{g}$ of rice kernels in $\mathrm{Y} \mathrm{ml}$ of distilled water (Table 3) are cooked for 30 minutes (20' with the steam cooker on and 10' off). Portions of $\mathrm{Z} g$ are analyzed in the texture analyzer; the result is the mean of $\mathrm{K}$ data and the determination is made in duplicate. 
Table 3. Parameters for the determination of hardness and stickiness

\begin{tabular}{ccccc}
\hline Analysis & $\mathrm{X}$ & $\mathrm{Y}$ & $\mathrm{Z}$ & $\mathrm{K}$ \\
\hline Hardness & $20 \mathrm{~g}$ & $38 \mathrm{ml}$ & $17 \mathrm{~g}$ & 6 \\
Stickiness & $8 \mathrm{~g}$ & $12 \mathrm{ml}$ & $2 \mathrm{~g}$ & 8 \\
\hline
\end{tabular}

The UNI ISO 14864:2004 [6] specifies a method to evaluate the gelatinization time of rice kernels during cooking. It is applied only to milled rice. The principle of the method consist in the determination of the time span between the immersion of the sample of rice into boiling water and the kernels becoming fully gelatinized that are evaluated by visual observation.

For the determination of amylose content, rice is ground to a very fine flour (Retsch ZM200 grinding system and sieving with a $150 \mu \mathrm{m}$ Endecotts sieve) to break up the endosperm structure in order to aid complete dispersion and gelatinization; the flour is then defatted. A test portion is dispersed in a sodium hydroxide solution, to an aliquot portion of which an iodine solution is added. The absorbance, at $720 \mathrm{~nm}$, of the color complex formed is then determined using a UV-VIS spectrophotometer (Lambda 25, Perkin Elmer). The amylose mass fraction of the sample is then read with a calibration graph, which is prepared using mixtures of potato amylose and amylopectin to make allowance for the effect of amylopectin on the colour of the amylose-iodine complex of the test solution (UNI EN ISO 6647-1:2008 [21]).

\subsection{Definition of the Modalities and Cooking Times}

To maintain the unique characteristics of the kernel in this context it is crucial that the cooking for the sensorial characterization is carried out in distilled water (Elix10, Millipore). In the cooking of rice a water intake due to the swelling of the starch granules, which is the main component of the kernel occurs, and a part of it passes into the cooking liquid (no editing, however, the nutritional value of the product). Precisely in this regard it is believed that the optimal cooking for the purpose of the study is for total absorption of the liquid during cooking, just to ensure that any component is not lost in the cooking step. It is therefore considered appropriate to maintain the cooking conditions adopted in the preparation of rice analysis of hardness (ratio water: rice $=1.9: 1$ ) [15].

\subsection{Sensory Evaluation}

The sensory evaluation were made in the ERSAF laboratory (constituted according to the ISO 8589:2007 [22]); the sensory profile (ISO 13299:2003 [23]) of each variety was carried out prior identification of perceived sensory characteristics (descriptors) that are measured quantitatively to define the perceived differences between different varieties of the same product.

\section{Results and Discussion}

We can see summarized below, the results emerged as a result of cooking tests to determine the appropriate cooking time of the different varieties, the results of sensory evaluation, of the chemical, physical and textural characterizations and a comparison between them.

\subsection{Cooking Times}

The tests of the preliminary determination of the correct cooking times to be applied to the different varieties (Table 4 ), were carried out both in the LCM and in the sensory analysis laboratory of ERSAF.

The times were determined by taste tests repeated at different cooking times with a panel of tasters.

Table 4. Cooking time adopted in the sensory analysis laboratory

\begin{tabular}{cc}
\hline Rice variety & Cooking time (minute) \\
\hline Aiace & 19 \\
Arborio & 17 \\
Baldo & 12 \\
Carnaroli & 17 \\
Gange & 16 \\
Loto & 16 \\
Sant'Andrea & 15 \\
Selenio & 15 \\
Thaibonnet & 19 \\
Vialone Nano & 13 \\
\hline
\end{tabular}

\subsection{Sensory Evaluation}

Sensory evaluation was carried out according to ISO 13299:2003.

The panel developed its own terminology and scored the tested varieties of rice through a shared discussion.

Reference standards were chosen by the panel and used in sensory evaluation.

The sensory profile is the complete description of the sensory properties of a product (rice), obtained by listing the sensory attributes and assigning an intensity value to each attribute. It is obtained by treating statistically the data originated by 11 judges (Fig. 1).

The elaboration was carried out through the Procustes Generalized Analysis (GPA) that is able to assess the existence of particular features that differentiate the samples and the presence of the level of agreement of the judges in identifying and measuring the characteristics (Fig. 2).

Evaluating the results show clearly that Gange is a very peculiar variety compared to all the others, for the following characteristics: odour of pop-corn, peanuts and crust of bread odours, sweet, hardness, friability, pop-corn and peanuts flavour. Gange is the only aromatic rice evaluated in this study! The Selenio variety differed in sourness, the Aiace in chewiness and the Arborio in bitterness and wood flavour. 


\subsection{Chemical, Physical and Textural Properties}

The selected varieties were characterized in the LCM obtaining the results reported in Table 6 .
All the results are reported with their extended uncertainties (specific coverage factors, $\mathrm{k}$, are specified at a level of 95\%) evaluated with a metrological or an olistic approach.

Table 5. Descriptors of rice

\begin{tabular}{|c|c|c|}
\hline & & Attributes \\
\hline \multirow{5}{*}{\multicolumn{2}{|c|}{ Sensory attributes perceptible by the olfactory organ }} & Popcorn \\
\hline & & Peanut \\
\hline & & Baked bread \\
\hline & & Bread-crust \\
\hline & & Nut \\
\hline \multirow{4}{*}{ Flavour (assessment by mouth) } & \multirow{3}{*}{ Taste } & Sweet \\
\hline & & Sour \\
\hline & & Bitter \\
\hline & $\begin{array}{l}\text { Sensory attributes perceptible by the olfactory } \\
\text { organ via the back of the nose when tasting }\end{array}$ & $\begin{array}{c}\text { The same as sensory attributes perceptible by the } \\
\text { olfactory organ }\end{array}$ \\
\hline \multirow{5}{*}{\multicolumn{2}{|c|}{ Texture }} & Hardness \\
\hline & & Solubility \\
\hline & & Fracturability \\
\hline & & Chewiness \\
\hline & & Adhesiveness \\
\hline
\end{tabular}

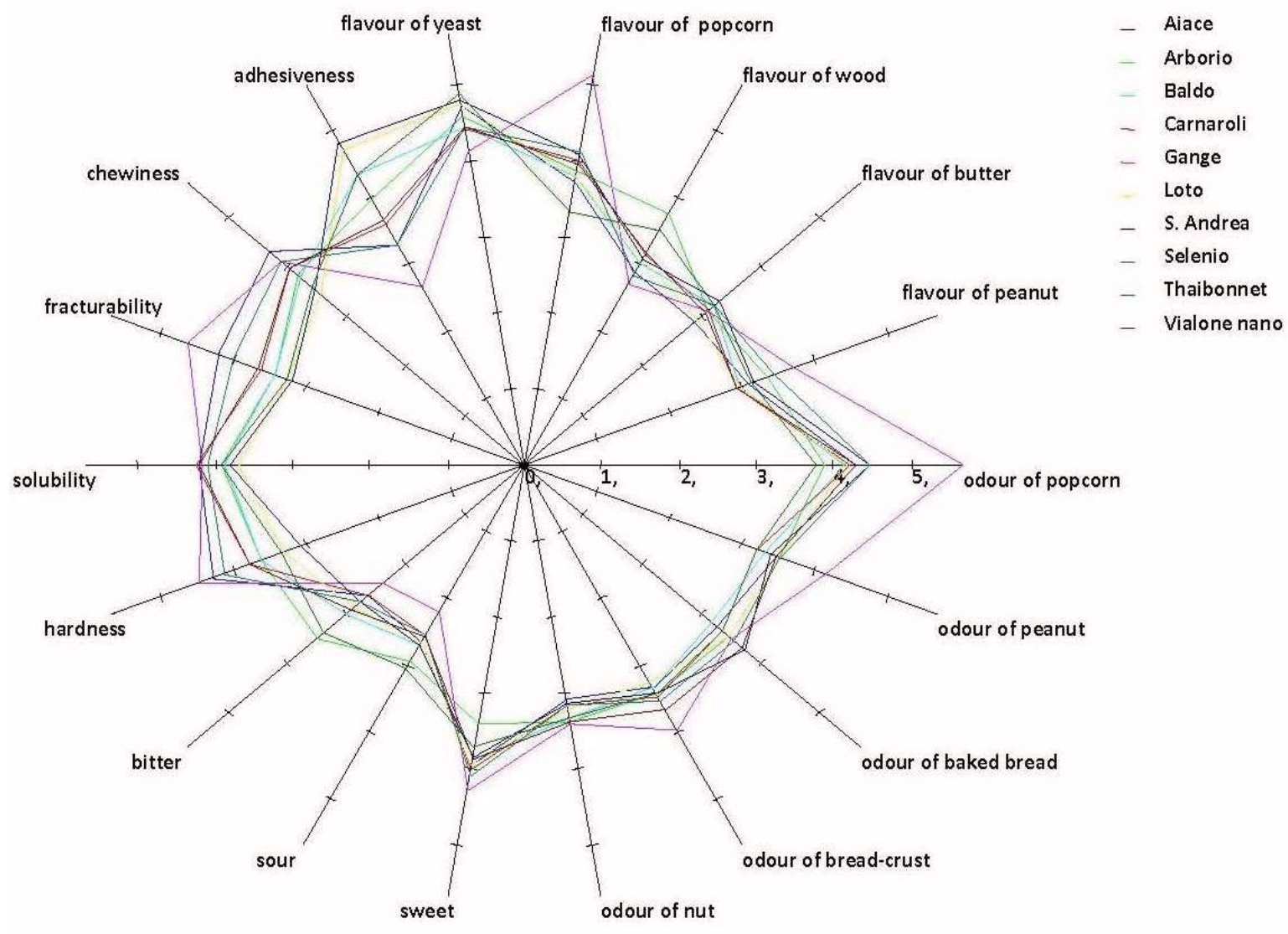

Figure 1. Spiderplot showing sensory profile of 10 Italian rice varieties 


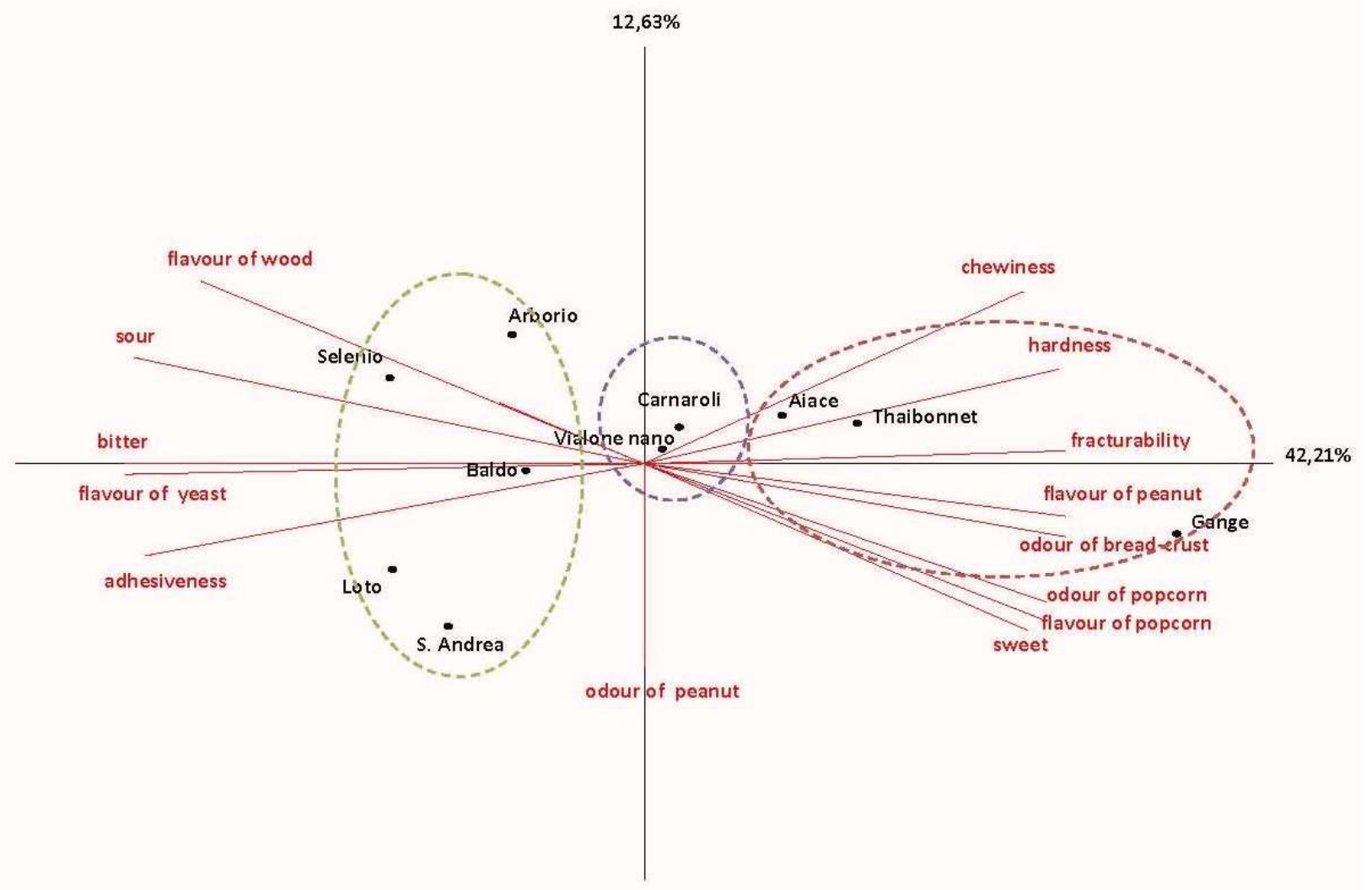

Figure 2. Graphical visualization of GPA for 10 Italian rice varieties

Table 6. Characterization of rice Italian varieties

\begin{tabular}{ccccccc}
\hline Rice variety & $\begin{array}{c}\text { Lenght } \\
{[\mathrm{mm}]} \\
(\mathrm{k}=2.26)\end{array}$ & $\begin{array}{c}\text { Width } \\
{[\mathrm{mm}]} \\
(\mathrm{k}=2.26)\end{array}$ & $\begin{array}{c}\text { Hardness } \\
{\left[\mathrm{kg} / \mathrm{cm}^{2}\right]} \\
(\mathrm{k}=2.06)\end{array}$ & $\begin{array}{c}\text { Stickiness [g.cm] } \\
(\mathrm{k}=2.16)\end{array}$ & $\begin{array}{c}\text { Amylose } \\
{[\mathrm{g} / 100 \mathrm{~g}]} \\
(\mathrm{k}=2)\end{array}$ & $\begin{array}{c}\text { Gel-time }[\mathrm{minute}] \\
(\mathrm{k}=2.16)\end{array}$ \\
\hline Aiace & $6.40 \pm 0.23$ & $2.40 \pm 0.09$ & $1.37 \pm 0.16$ & $0.92 \pm 0.23$ & $24.9 \pm 4.6$ & $22.55 \pm 2.32$ \\
Arborio & $6.80 \pm 0.24$ & $3.40 \pm 0.12$ & $0.82 \pm 0.16$ & $3.14 \pm 0.73$ & $15.3 \pm 3.2$ & $19.53 \pm 2.32$ \\
Baldo & $6.90 \pm 0.24$ & $3.10 \pm 0.11$ & $0.86 \pm 0.16$ & $3.87 \pm 0.89$ & $17.9 \pm 3.5$ & $19.85 \pm 2.32$ \\
Carnaroli & $6.60 \pm 0.23$ & $3.10 \pm 0.11$ & $1.11 \pm 0.16$ & $0.93 \pm 0.23$ & $20.6 \pm 3.9$ & $19.72 \pm 2.32$ \\
Gange & $7.20 \pm 0.25$ & $2.20 \pm 0.08$ & $1.19 \pm 0.16$ & $0.39 \pm 0.11$ & $23.6 \pm 4.4$ & $21.62 \pm 2.23$ \\
Loto & $6.00 \pm 0.21$ & $2.90 \pm 0.10$ & $0.71 \pm 0.16$ & $5.13 \pm 1.17$ & $14.9 \pm 3.1$ & $18.87 \pm 2.32$ \\
Sant'Andrea & $6.20 \pm 0.22$ & $3.10 \pm 0.11$ & $0.75 \pm 0.16$ & $4.43 \pm 1.02$ & $16.5 \pm 3.3$ & $19.50 \pm 2.23$ \\
Selenio & $4.70 \pm 0.17$ & $2.80 \pm 0.10$ & $0.77 \pm 0.16$ & $3.90 \pm 0.90$ & $16.7 \pm 3.4$ & $19.13 \pm 2.22$ \\
Thaibonnet & $7.20 \pm 0.25$ & $2.10 \pm 0.08$ & $1.13 \pm 0.16$ & $0.41 \pm 0.11$ & $25.3 \pm 4.7$ & $21.67 \pm 2.23$ \\
Vialone Nano & $5.60 \pm 0.20$ & $3.30 \pm 0.12$ & $1.10 \pm 0.16$ & $0.91 \pm 0.23$ & $22.4 \pm 4.2$ & $15.95 \pm 1.47$ \\
\hline
\end{tabular}

For each variety, the dimensional characteristics (length and width) ensure their correct classification in accordance with EC Regulation 1308/2013 [4]. The gelatinization times are typical for each rice varieties and are used, in the following paragraphs, to deduce the approximate cooking times, through the application of the formula "gel-time $20 \% "$ " [10]. The hardness and stickiness values are consistent with the amylose content and follow the trend described above.
As a result of the sensory characterization carried out in ERSAF laboratory (3.1), it is possible to group the different varieties of rice according to the groups shown in Figure 2 and indicated in Table 6 according to their different chromaticity.

It is possible to make an assessment of the individual characterization of each variety and represent it using radar charts. They are overlapped and reported for group membership (as reported in Table 6). 


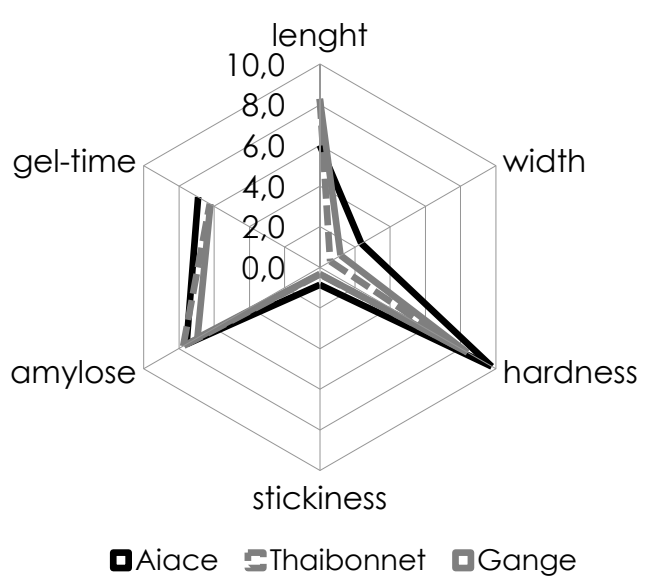

Figure 3. Aiace, Thaibonnet, Gange group

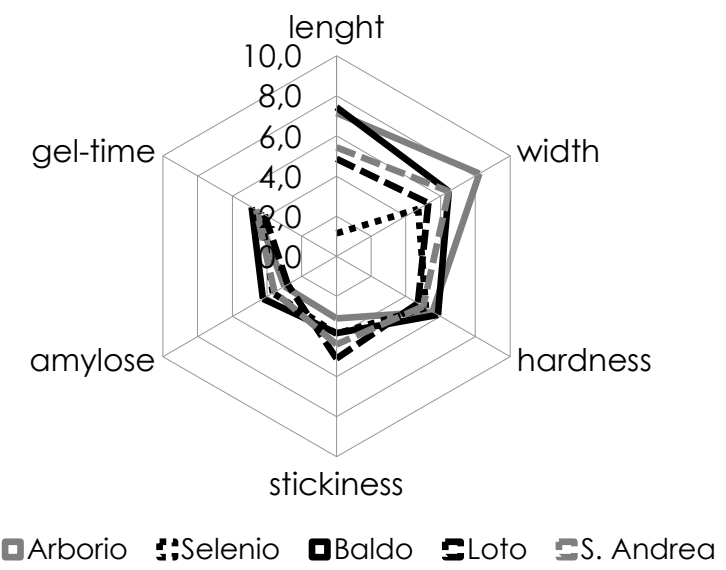

Figure 4. Arborio, Selenio, Baldo, Loto, Sant' Andrea group

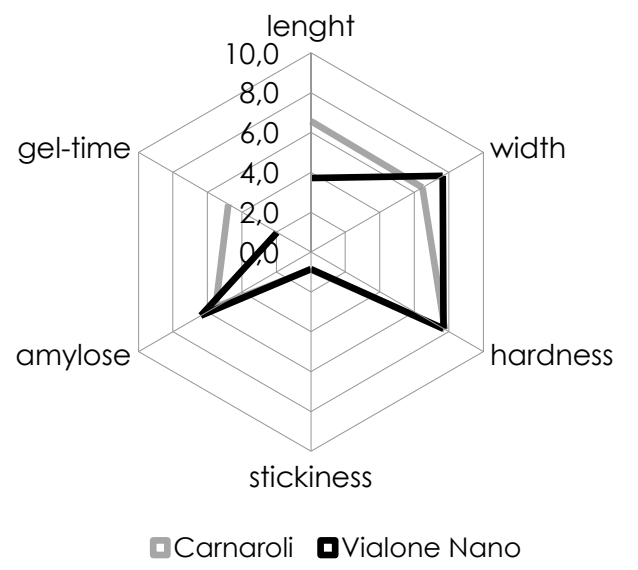

Figure 5. Carnaroli, Vialone Nano group

The data reported in Table 6 arises similarities between the varieties Aiace, Thaibonnet and Gange (similar biometric characters, gel-time, amylose content, hardness and stickiness).
There is a confirmation of their similarity even after the sensory characterization (Figure 3), which shows a further peculiarity of the Ganges, as the sole aromatic rice. These varieties are characterized by high amylose content $(>24$ $\mathrm{g} / 100 \mathrm{~g}$ ) and consequent high hardness and low stickiness. They exhibit a similar gelatinization time (about 22 minutes), which indicates, through the "gel-time $-20 \%$ " calculation [10], a cooking time around 17.6 minutes, quite similar to that reported in Table 4.

The second group (taken from Figure 4) consists of dissimilar varieties: Arborio, Selenio, Baldo, Loto and Sant'Andrea. However they are all comparable for their low amylose content $(10-19 \mathrm{~g} / 100 \mathrm{~g})$ and consequent low hardness and high stickiness. Also the gel-times are similar (about 19 minutes) and provide an approximate cooking time of 15.2 minutes. Biometrics characteristics are significantly different (the varieties have in fact different classification, as reported in Table 2, according to the application of the EC Reg. 1308/2013 [4]).

The third group emerged from Figure 5 includes Carnaroli and Vialone Nano, different in dimensionality (respectively a long A and long B kernel), but comparable for the medium amylose content $(20-24 \mathrm{~g} / 100 \mathrm{~g})$ and the consequent hardness and stickiness. They are heterogeneous according to the parameter gel-time, respectively: 19.7 minutes for Carnaroli (which gives a cooking time of 15.8 minutes) and 15.9 minutes for Vialone Nano (12.8 minutes for calculated cooking time).

Comparing the chemical-physical and textural determinations with the sensory one, a close analogy between the sensory character chewiness and hardness emerged, as well as between adhesiveness and stickiness. This is particularly evident for the variety Aiace which presents the highest hardness and the highest score for the character chewiness. The varieties Loto and Sant' Andrea are the ones with the most marked character of adhesiveness and which have the highest value of stickiness. The score of the character of chewiness for both, is the lowest among the varieties and similarly their hardness is the lowest recorded.

\subsection{PCA on Chemical, Physical and Textural Properties}

After the data normalization of the results in Table 6, it is possible to draw the Principal Component Analysis (PCA). Two sets of scatter plots are considered: [PC1 and PC2]; $[\mathrm{PC} 1$ and $\mathrm{PC} 3]$ as shown in Figure 6.

[PC1 and PC2]: confirmed the analogy of the first group for gel-time and length; in the second group the stickiness is similar.

[PC1 and PC3]: put into evidence the heterogeneity of the second group. 

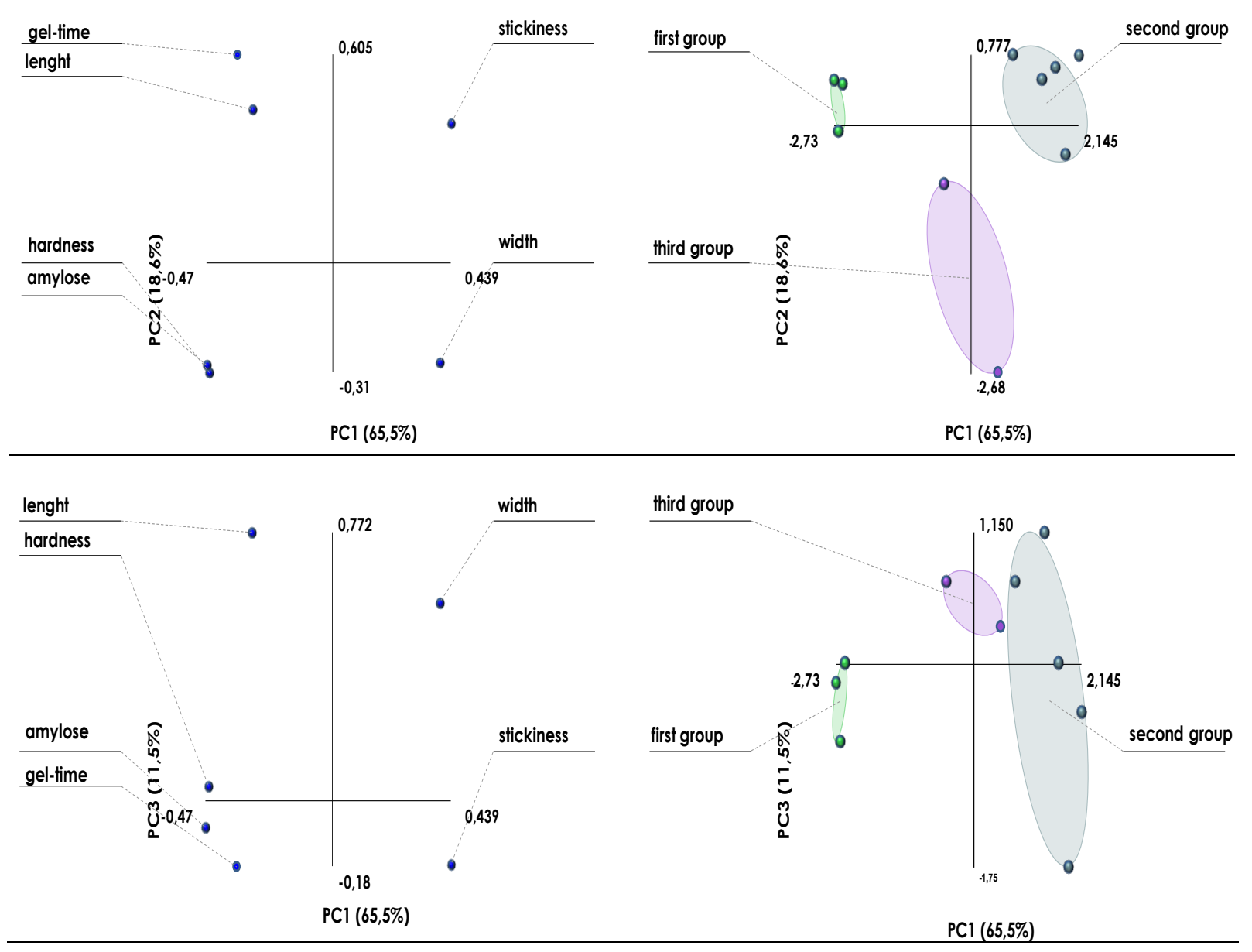

Figure 6. PCA on Table 1 data. Left: variables (loadings); right: samples (score)

\section{Conclusions}

From this work it appears that there is agreement between the sensory analysis and the chemical physical and textural characterization of milled rice. In fact there is an analogy between the texture analysis (hardness and stickiness) and some sensory characters (respectively, chewiness and adhesiveness). Noteworthy is the fact that this correspondence is marked even if the experimental data are obtained with different analytical techniques (instrumental and sensory analysis) and the methods of preparing the samples are different. From a practical point of view, the tests carried out with the equipment, in particular the above-mentioned analyses of texture (hardness and stickiness) are faster in execution and the usability of the results than sensory analysis. On the other hand we must not forget that rice is a staple food, so the sensory characterization by a panel of tasters, representing consumers who use the food rice, is important. The sensory characterization undoubtedly provides a more complete and accurate information than the current instrumental characterization that however provides a good approximation (on some parameters) given the demonstrated agreement between the results.

Thanks to this work today there is an available card of sensory evaluation of rice varieties (see Table 4) that represents a high level of innovation as it allows to express objective decisions about the quality of the product, comparing the sensory profiles of the different varieties and explaining with them the consumer preferences.

The future perspective of this work is to use the card for sensory evaluation of rice in combination with the product analysis to bring out the peculiarities linked to the territory.

\section{REFERENCES}

[1] AA.VV. Il riso, Bayer CropScience, Ed. Script, Bologna (2008).

[2] Source: data Ente Nazionale Risi.

[3] C. E. Chávez-Murillo, Y. Wang, A. G. Quintero-Gutierrez, and L. A. Bello-Pérez. Physicochemical, Textural, and Nutritional Characterization of Mexican Rice Cultivars, Cereal Chemistry, vol. 88, 245-252, 2011.

[4] Regulation EU.No 1308/2013 of the European Parliament and of the Council of 17 December 2013..

[5] H. Yamamoto, E. Makita, Y. Oki, M. Otani. Flow characteristics and gelatinization kinetics of rice starch under 
strong alkali conditions, Food Hydrocolloid, 20:9-20, 2006.

[6] ISO 14864:2004. Rice - Evaluation of Gelatinization time during cooking.

[7] A. Tinarelli. Appunti di Merceologia - Il Riso nelle sue caratteristiche e Qualità. Ed. Saviolo, 1999 (in Italian).

[8] F. Ranghino F. Valutazione della resistenza del riso alla cottura, in base al tempo di gelatinizzazione dei granelli, Il Riso, XV: 117-127, 1966.

[9] V. Vidal, B. Pons, J. Brunnschweller, S. Handshuin, X. Rouau, C. Metres. Cooking Behavior of Rice in Relation to kernel Physicochemical and Structural Properties, Journal Agrocoltural Food Chemistry, 55: 336-346, 2007.

[10] C. Simonelli, M. Cormegna, L. Galassi, P. Bianchi. Cooking Time and Gelatinization Time of Rice Italian Varieties, Journal of Food Science and Nutrition, 2 (42): 37-43, 2013.

[11] Z. Zhoust, K. Robards, S. Helliwell, C. Blanchard. Ageing of Stored Rice: Changes in Chemical and Physical Attributes, Journal of Cereal Science 33, 2001.

[12] E.T. Champagne. Rice: Chemistry and Technology - Third Edition. U.S. Department of Agriculture Research Service Southern Regional Research Center, New Orleans, Louisiana, 2004.

[13] A. Suwannaporn, S. Pitiphunpong, S. Champangern, Classification of rice amylose content by discriminant analysis of physicochemical properties, Starch/Stärke, 59, 171-177, 2007.
[14] ISO 6658:2005 Sensory analysis - Methodology - General guidance

[15] Galassi L. e Simonelli C., Caratterizzazione sensoriale e chimico-merceologica di riso, ERSAF, Regione Lombardia (2011).

[16] DM 13/11/08, GU N. 22 DEL 28/01/2009: Denomination of the variety of rice and corresponding variety of rice and attribution to the group of belonging.

[17] ISO 11746:2012. Rice - Determination of Biometrics Characteristics of Kernels.

[18] ISO 11747:2012. Rice - Determination of Rice Kernel Resistance to Extrusion after Cooking.

[19] Laboratorio Chimico Merceologico (ENR) MP14 rev.09: 2013. Rice - Determination of Stickiness after Cooking (Internal Method).

[20] C. Simonelli, M. Cormegna, F. Marinone Albini, M. Radicchi. Validation of a Method for determining the Stickiness of Rice, Journal of Food Science and Nutrition, 1 (43): 23-36, 2014 (in Italian).

[21] ISO 6647-1:2008. Rice - Determination of Amylose content Part 1: Reference method (ISO 6647-1:2007).

[22] ISO 8589:2007 Sensory analysis-General guidance for the design of test rooms

[23] ISO 13299:2003 Sensory analysis-Methodology-General guidance for establishing a sensory profile 